\title{
Símbolos modernistas en la ilustración madrileña
}

\author{
SAgrario Aznar
}

Alrededor de 1900 las formas y los temas modernistas se convierten en el lenguaje común de una Europa en la que la burguesia capitalista va teniendo cada vez más fuerza. Las pequeñas particularidades nacionales que puedan aparecer no anulan su carácter generalizado, gracias al cual se ha podido hablar de un "último estilo internacional». La enorme riqueza iconográfica del "Art. Nouveau", desde el melancólico cisne a los girasoles pasando por la maligna sirena o el elegante pavo real, no pueden ser reducidos al simple calificativo de "simbolos decadentes". Evidentemente, la promesa de rejuvenecimiento que conlleva el Modernismo descansa en un repertorio de temas simbolistas heredados, fundamentalmente, de los "poetas malditos", y adoptados, como bagaje cultural, por la misma burguesía que había marginado a sus creadores. Pero también aparece un tipo de actitud más vitalista ante el arte: los "modernistas prácticos", como los califica Amaya', que creen compatible el binomio "arte-industria" y siguen la llamada de la tecnologia para poder crear el nuevo estilo de la sociedad industrial. Sus temas se liberan de las languideces simbolistas para mostrarnos su propio mundo contemporáneo: sus fiestas, sus problemas y, como no, sus máquinas.

La elegante vida de la ópera y los cabarets nocturnos es un lugar común para casi todos los ilustradores, aunque son los más tradicionales (como Cecilio Plá, Méndez Bringa o Huertas) los que nos lo muestran detalladamente en todo su esplendor. Sin embargo, otros como Adolfo Lozano Sidro (1872-1935) saben adoptar las formas decorativas «Nouveau" para plasmar toda la ostentación de elegancia de la sociedad de la

\footnotetext{
1 Amaya, Art Nouveau, Madrid, 1973, pág. 6.
} 
"Belle Epoque", una alegre sociedad que se niega a analizar los problemas endémicos que sufria España. El caciquismo, el mundo de los marginados - la hipocresía religiosa serán, por el contrario, los temas básicos del catalán Mariano Foix (1860-1914). Su intento de conectar el Modernismo con la crítica social hace que sus dibujos jamás caigan en un pintoresquismo que, generalizado en la pintura y la ilustración de la época, lo avasalla todo. Él prefiere, con sus abatidas siluetas negras, seguir la línea de Steinlen en Francia, mostrándonos problemas como el paro o la crisis social, tristes consecuencias de la generalización de las máquinas.

Pero no van a ser sólo sociales los cambios provocados por la máciuina. Para el arte, el maquinismo va a suponer un cambio radical en lo que se refiere a la visión de «lo natural». Como muy bien señala Delevoy², la industrialización empieza a transformar las tradicionales relaciones hombre-naturaleza: "el influjo de la naturaleza en el hombre disminuye al tiempo que aumenta el poder de acción del hombre sobre la misma". En consecuencia, y a pesar de las enseñanzas de Ruskin, que veia en la representación minuciosa de las formas naturales un sentido religioso ("toda noble ornamentación es la expresión del placer del hombre en el trabajo de Dios" $\left.{ }^{3}\right)$, aparecen unos dibujantes y decoradores, entre los que se encuentran Eulogio Varela (1868-1955) y José Arija (muerto en 1920), que no quieren hacer una fácil transcripción de las formas de las plantas sino que prefieren transformar y trascender la Naturaleza, abstrayéndola en líneas altamente decorativas.

Esta forma de distanciación de lo natural se relaciona con el deseo de evasión de los modernistas-simbolistas, soñadores y visionarios, cuya faceta más superficial se plasma en el gusto por el misterio, el ocultismo, el erotismo extravagante o la arqueologia exótica. Detestaban los héroes de Zola para volcarse en la llamada por Yeats tragic generation cuyo más válido representante podría ser Luis II de Baviera.

Su deseo de evadirse fuera del mundo llevó a Baudelaire al láudano, a Verlaine a la absenta y a Oscar Wilde a un destino trágico del que su sofisticado refinamiento no le pudo salvar. Secundando el "Naturaleza, nada tuyo me conmueve", de Verlaine ${ }^{4}$, Wilde se lanza a buscar un mundo

2 Delevor, Dimensiones del siglo XX, Madrid, 1965, pág. 135.

3 MADSEN, Sources of Art Nouveau, 1975, pág. 166.

"Principio de la poesia "La angustia", en Verlaine, Poesia completa, Madrid, Río Nuevo, 1979, pág. 45. 
en el que todos los mitos pueden convivir, un mundo antinatural que sólo es posible en el arte:

\begin{abstract}
"Seremos dichosos cuando por fin no se crea en lo evidente y la verdad gima encadenada y la leyenda retorne a la tierra; todo el aspecto del mundo cambiará entonces ante nuestros ojos asombrados. El fénix volará desde su nido de llamas a los aires, acariciaremos a los basiliscos $y$, en nuestras cuadras, el hipogrifo golpeará el suelo con sus cascos de oro; y por encima de nuestras cabezas girará el Pájaro Azul, cantando cosas maravillosas e imposibles, cosas que son deliciosas y no suceden nunca, cosas que no existen, pero debieran existirn ${ }^{5}$.
\end{abstract}

El ansia modernista por dar la espalda a la realidad se plasma tanto en el tiempo como en el espacio. El gusto por lo japonés, cuya influencia no es só!o formal (colores planos, sentido lineal o bidimensionalidad), sino también temática, como comprobamos en algunas ilustraciones de Vare$1 a^{6}$, forma parte de un gusto por los lujos y refinamientos orientales que pervivirá en años posteriores, incluso después de la Primera Guerra Mundial, gracias, en gran parte, a los Ballets Rusos que, tras el éxito de "Sheherezade" en 1910, imponen la exótica estética de León Bakst en todos los campos de las artes decorativas.

Por otro lado, la evasión en el tiempo abarca muy distintos períodos. En este sentido, el Art Nouveau sabe conectar con casi todos los revivals que habían tenido lugar en el siglo XIX, pero, sobre todo, con el rococó, el celta y el gótico.

El Neo-rococó se da fundamentalmente en Francia como reacción al Imperio neoclásico de Napoleón, cuando sube al trono Luis XVIII. La impronta femenina de este estilo y elementos formales tales como su elegante uso de las flores o su torsión de las formas, más acusada incluso que en el Rococó original, le hacen muy favorable a la combinación con el Art Nouveau. En casi ninguno de los ilustradores españoles, incluidos los de los años 20, falta el tema de la mujer rococó con el pequeño Cupido, pero, a principios de siglo, es Alonso Pérez el que casi lo monopoliza en sus portadas para el Blanco y Negro.

No ocurre lo mismo con el revival celta que sólo aparece en España en algunos enmarques de portadas, hechos por Arija o Varela con los peculiares entrelazamientos de animales fantásticos y formas vegetales. En realidad, es un movimiento estético casi exclusivamente inglés por ra-

5 Exposıcıon, Simbolismo en la pintura francesa, Madrid, Museo Español de Arte Contemporáneo, 1972, pág. 22.

6 Varela y Sartorio, Portada del Blanco y Negro, 16 de febrero de 1901. 
zones heredadas del nacionalismo romántico. Empezó en 1889 con Wanderings of Oisin and Other Poems de W.B. YEATS, y en los años noventa se extendió a las artes decorativas, hasta que a finales de siglo convive con el Art Nouveau?

Sin embargo, el neogótico, también de origen inglés, consigue generalizarse mucho más como tema en Europa. Empezó en los años cincuenta con las leyendas del rey Arturo, que encantaban a Ruskin, autor de Piedras de Venecia y de Las siete lámparas de la arquitectura, y que se generalizaron en 1857 con la decoración de Rossetti, Morris y Burne-Jones para el edificio del Oxford Union, apoyados por la figura literaria de Swiburne. Fue Morris el que llevó el revival a las artes aplicadas y su gusto por lo medieval pasó al continente conectando con la corriente wagneriana. La afición por Wagner y sus temas habia surgido en Alemania repercutiendo fuertemente en Francia sobre todo después de la reivindicación de este músico que llevó a cabo Villiers D'Isle Adams en sus crónicas semanales para la Revue des Lettres et des Arts desde 1867. En España, sin embargo, no es un tema de mucha aceptación, a pesar de que las románticas óperas de Wagner se representaban cada temporada en Madrid, y parece que casi exclusivamente Arija toca el tema en algunas ocasiones.

En Madrid tienen mucha más divulgación los temas simbolistas adoptados por el Art Nouveau. Tanto los ilustradores tradicionales, como los más avanzados, utilizan temas como la mujer fatal, el cisne, el pavo real o las sirenas. Eulogio Varela en 1900, y Chiorino en 1901, hacen unas series de ilustraciones basadas en temas florales claramente simbólicos. La humilde violeta, el vital girasol o la fúnebre malva aparecen entrelazados con las mujeres en formas tan decorativas que llegan a identificarse.

Es, sin duda, la mujer el tema más importante a finales del siglo pasado. El tipo de mujer que embrujó a Breton cuando visitó el Museo de Gustave Moreau, es una clara herencia romántica en la que el eterno femenino se desarrolla tanto en la virgen como en la sirena. Esta ambivalencia de mujer pura-mujer fatal aparece constantemente en todas las ilustraciones de principio de siglo llegando incluso hasta los años veinte. Pero, de las dos, la que prevalece es la mujer maligna, enigmática, que enreda al hombre en su larga cabellera cantada por Baudelaire en Las flores del $m^{\beta}{ }^{\beta}$, y que además resulta muy decorativa como tema para los dibujantes.

\footnotetext{
7 Un claro ejemplo es la capilla de Compton, Surrey, hecha a partir de un diseño de Mary Watts, esposa del pintor prerrafaelista G.F. Watts, en la que los azulejos neoceltas conviven con un interior Nouveau.

8 Baudelaire, Las flores del mal, Madrid, Edaf, 1981, págs. 60-61. Poema titulado "La cabellera".
} 
Es la mujer araña de Cecilio Plá (1860-1934) que lleva irremediablemente al hombre a la perdición o a la muerte. Salomé, Judith o la cortesana Tais son lugares comunes en la decoración Nouveau, ayudadas, en gran parte, por Beardsley y Klimt. Eros y Thanatos se urien en ellas. La mujer es la esfinge, el eterno femenino es la incógnita, y, aunque Edipo la vence, podemos preguntarnos con Hoffstätter:

\footnotetext{
“¿Dónde está actualmente Edipo? Le fue concedida la resolución del enigma femenino, pero fue una excepción y las estinges no murieron con él» ${ }^{9}$.
}

Algunos animales como la mariposa, el cisne o el pavo real pueden aparecer frecuentemente unidos a la figura femenina. La mariposa mantiene una relación clara asociada a la idea de la fragilidad, y el pavo real, por su inútil belleza, es un tema muy apto para la estética Nouveau. Pero el caso del cisne es bastante más complicado. Se trata de un signo plurivalente que puede reflejar las cosas más contradictorias. Para Baudelaire y Mallarmé es la impotencia, el trágico destino del poeta ante la realidad, igual que el albatros; para Rubén Dario es la duda, la incógnita reflejada por su largo cuello; para Dario Herrera el erótico cisne negro que retoma el mito de Leda, es la maldad ${ }^{10}$; pero también puede reflejar la pureza en su blancura o la Muerte con su canto. La decoración del Art Nouveau convierte al cisne en un símbolo más trivial asociado, en gran medida, a las voluptuosidades de los jardines de Versalles, pero tácitamente se mantiene el enigma de su significado.

Normalmente, el cisne aparece en pequeños lagos (aguas estancadas también muy frecuentes en el melancólico simbolismo) de remotos parques. Aunque en Rubén Dario los parques son versallescos y exóticos, llenos de risas y de pavos reales, los de Juan Ramón Jiménez o ios de Verlaine son tristes y solitarios. En ellos un melancólico surtidor es el único canto que acompaña a las siluetas negras que los cruzan. La idea de lo crepuscular, lo fugaz, lo marchito, está unida a este parque, paraíso perdido, único reducto de la Naturaleza en la ciudad La mujer sentada al borde de un lago del parque, en el crepúsculo, mirando un cisne, es un tema que aparece constantemente en las portadas del Blanco y Negro, uniendo, de este modo, todos los simbolos: la esfinge, la incógnita, la fugacidad y la melancolía.

También, por último, el tema del carnaval, de clara herencia simbolista, es fundamental en la ilustración madrileña, gracias, en gran parte, a los

\footnotetext{
9 Hoffstatter, Gustave Moreau, Madrid, 1980, pág. 97.

10 Dario Herrera, La nueva Leda, 1903.
} 
Bailes de Máscaras del Círculo de Bellas Artes y a los organizados por la Asociación de Escritores y Artistas, que, desde 1891, se convertirán en uno de los acontecimientos sociales más populares y característicos de Madrid. Absolutamente todos los ilustradores, pero de manera muy especial Méndez Bringa o Cecilio Plá, utilizan el tema de la mujer con antifaz en un baile de disfraces. La máscara, los bailes y la ambigüedad son formas básicas de la iconografía del Carnaval, pero, sin duda, es Pierrot, héroe del pesimismo y la melancolia, del amor imposible por Colombine, el tema más representado, sobre todo por dibujantes que adoptan muy tempranamente las formas Nouveau, como Varela o el catalán Apeles Mestres.

Todo este repertorio de temas modernistas son el reflejo de los gustos y actitudes de una sociedad que conecta abrumadoramente con nuestro "fin de siglo". Su deseo de evasión en paraísos perdidos o artificiales, y su enorme vitalidad al enfrentarse con el problema de la máquina, son temas que todavía hoy prevalecen en nuestra sociedad, y que han pervivido a través de los años veinte, cuarenta o sesenta, gracias al Decó y al Pop Art, llegando a formar un "lenguaje de siglo" que ha sobrevivido a todas las vanguardias artísticas. 


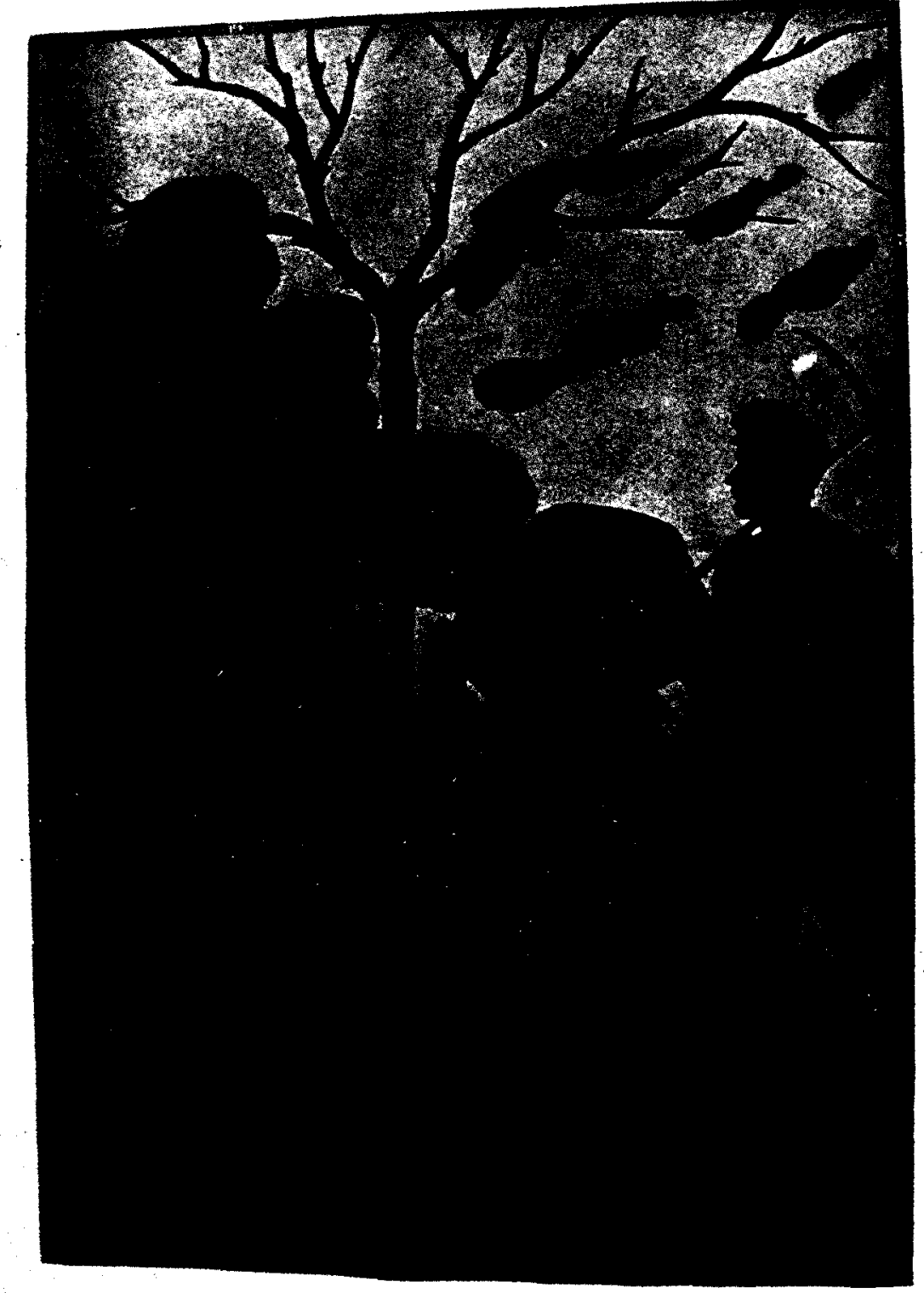

Fig. 1. Poix. "Blanco y Negro». 20 febrero, 1904. 


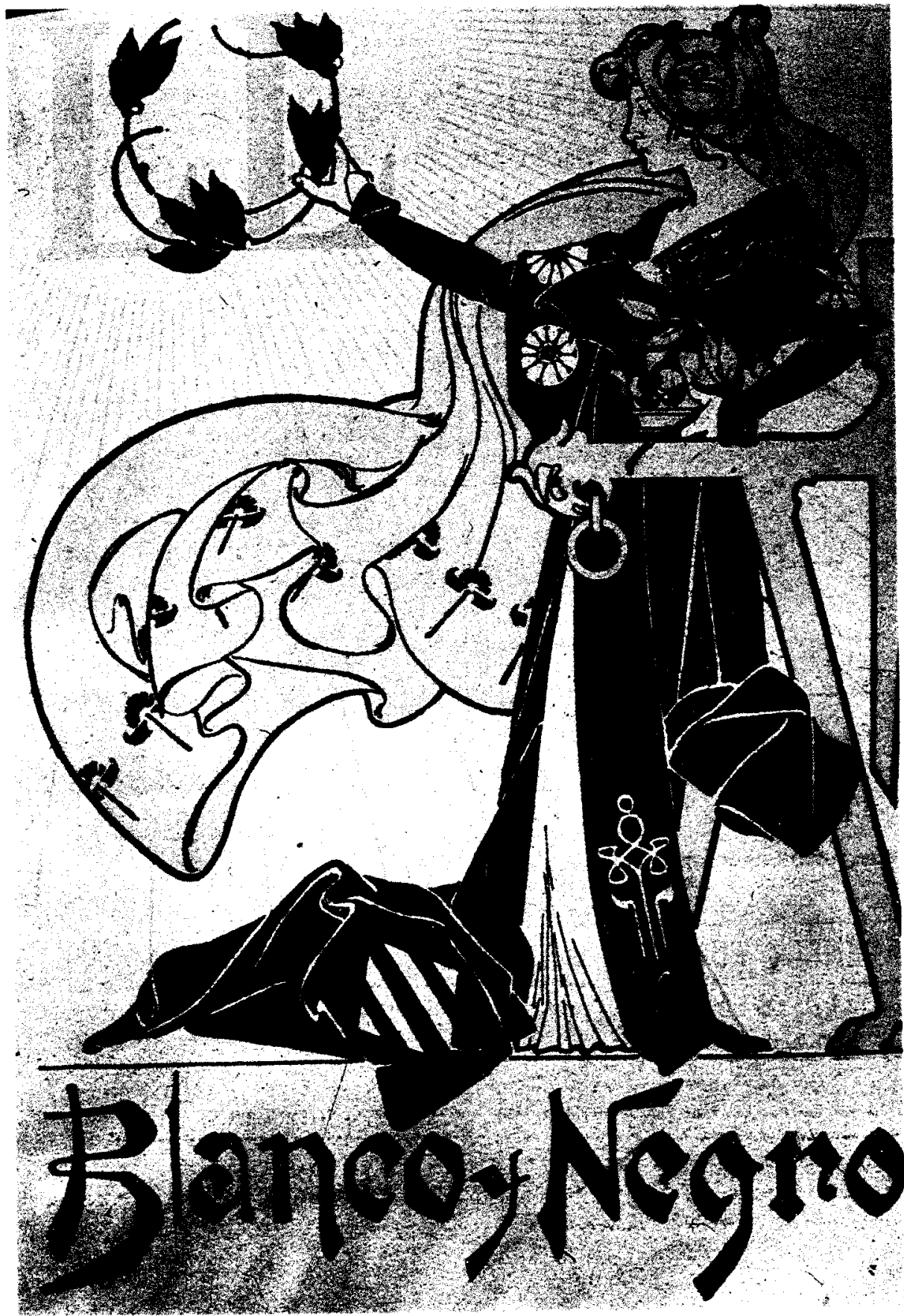

Fig. 2. Varela. "Blanco y Negro». 13 abril, 1901 


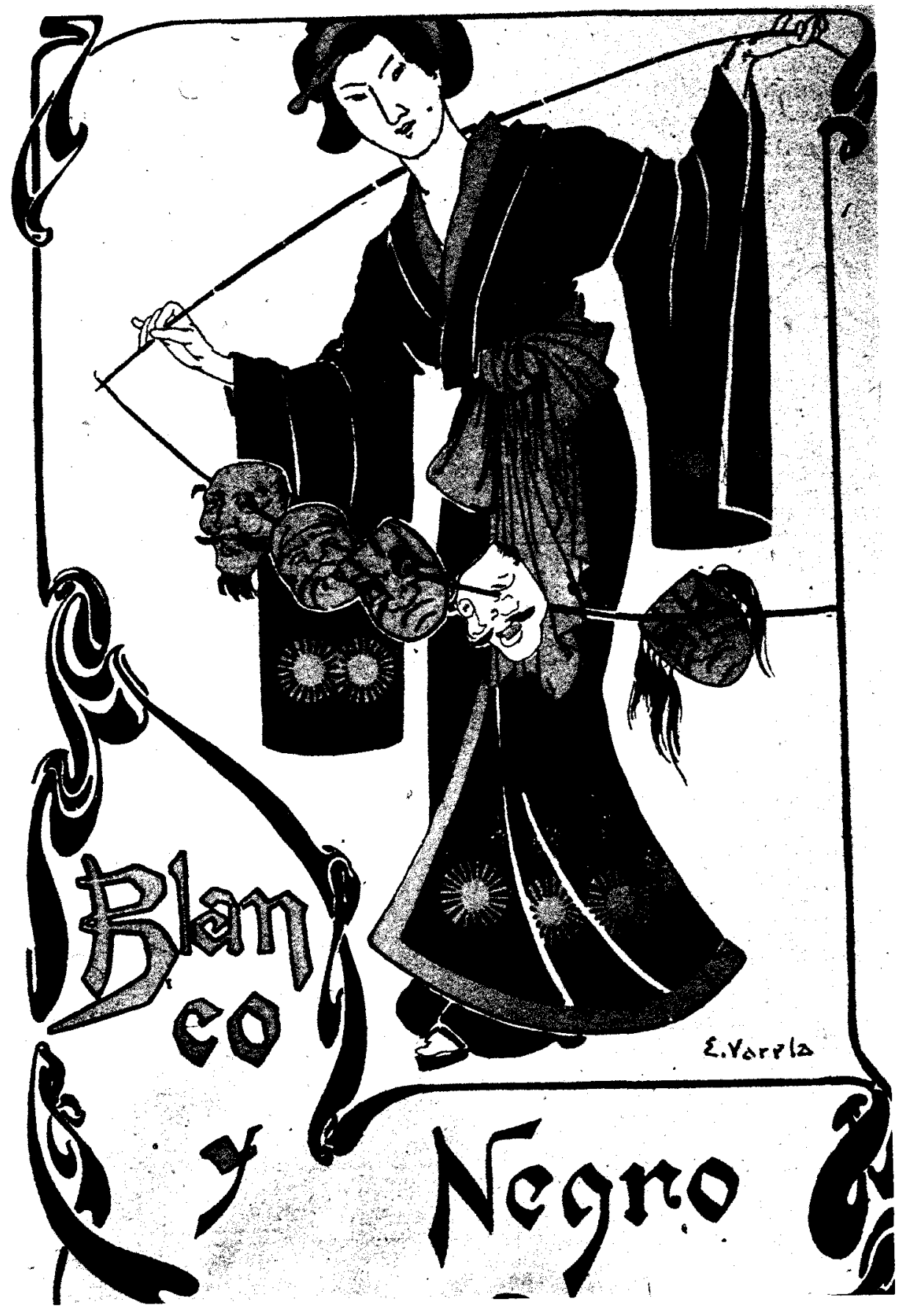

Fig. 3. Varela. Portada “Blanco y Negro". (16 febrero, 1901). 

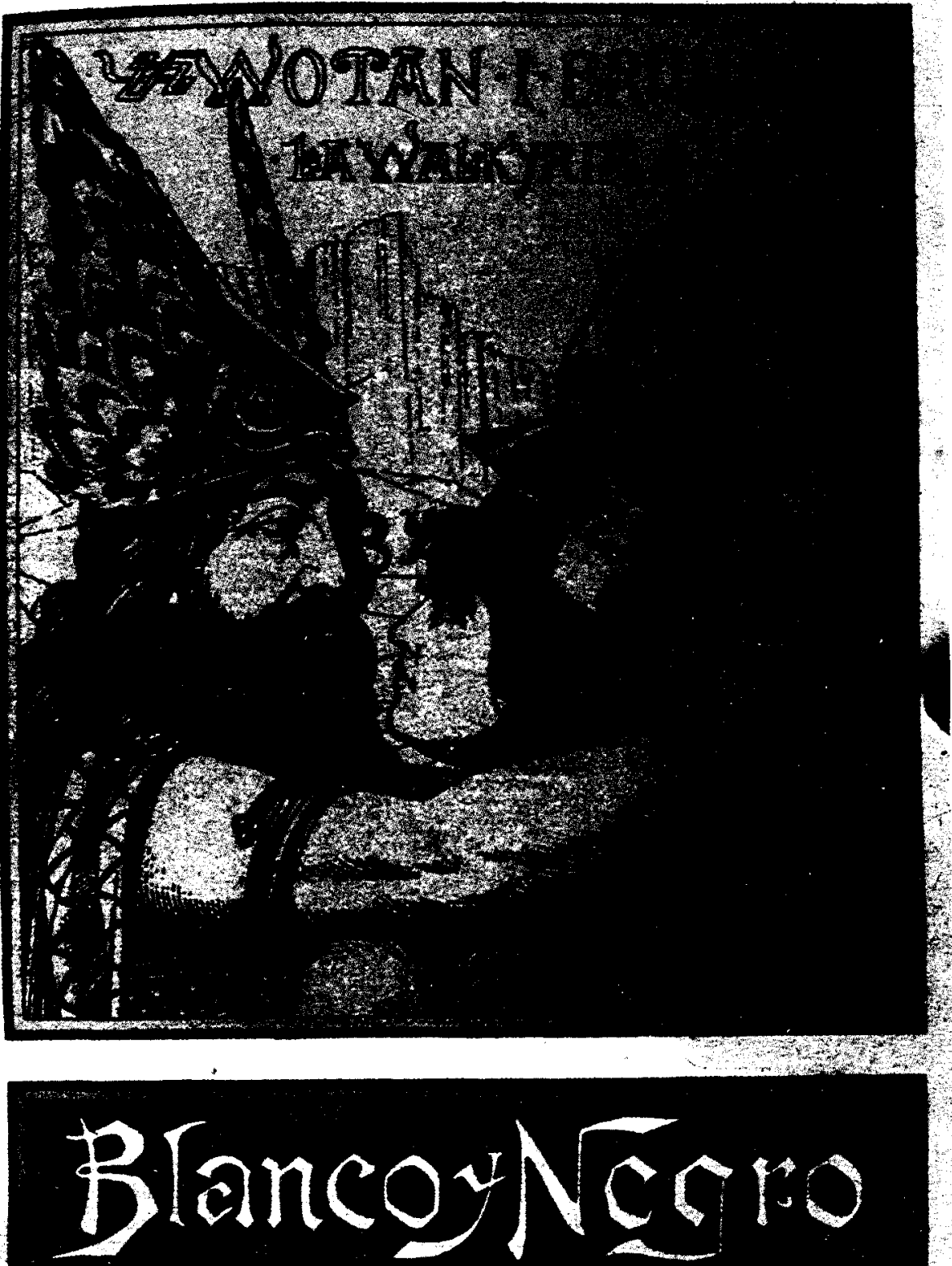

s.t.

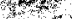

Fig. 4. Arija. Portada “Blanco y Negro». (23 noviembre, 1901). 


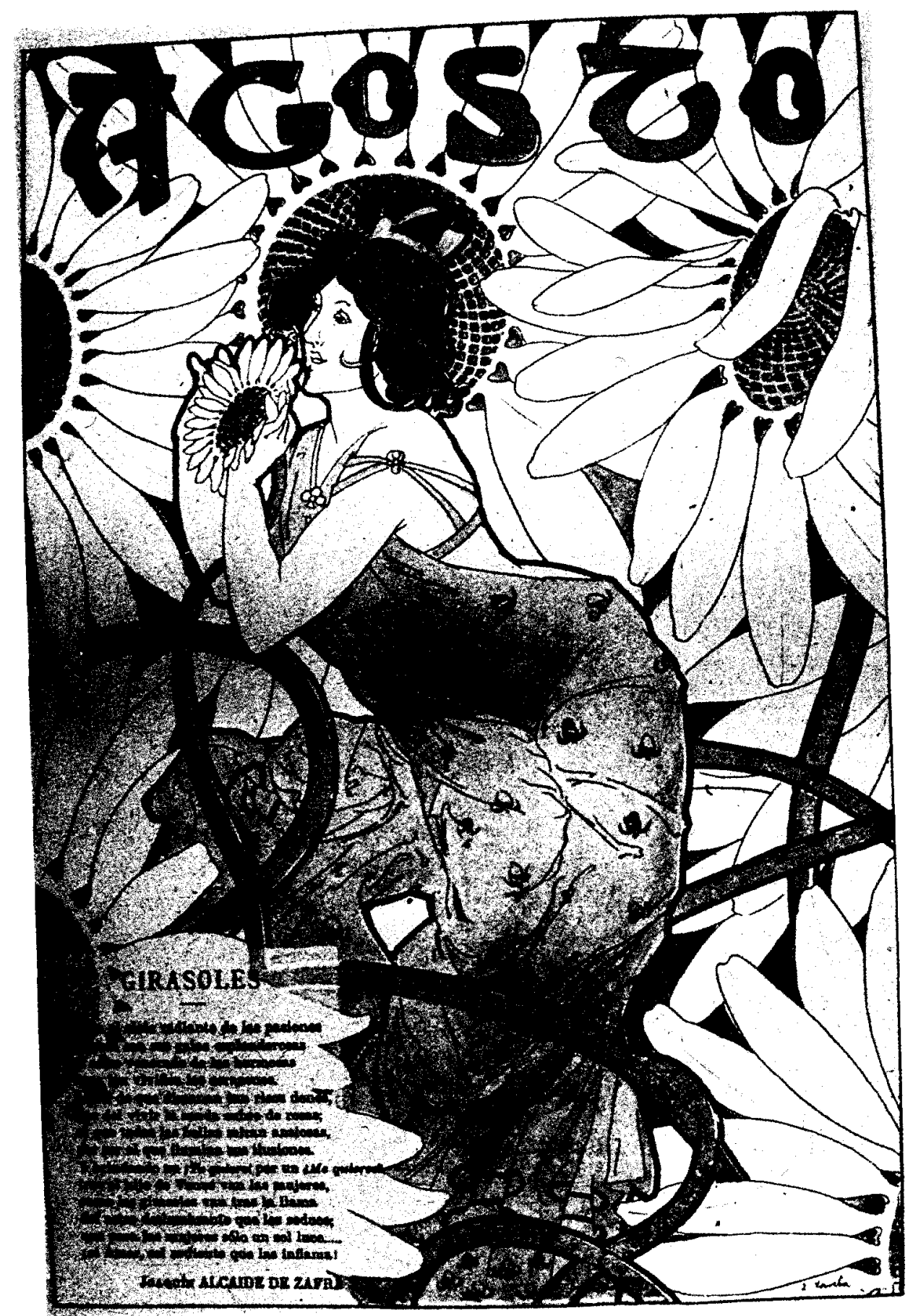

Fig. 5. Varela. “Blanco y Negro». 1 enero, 1900. 


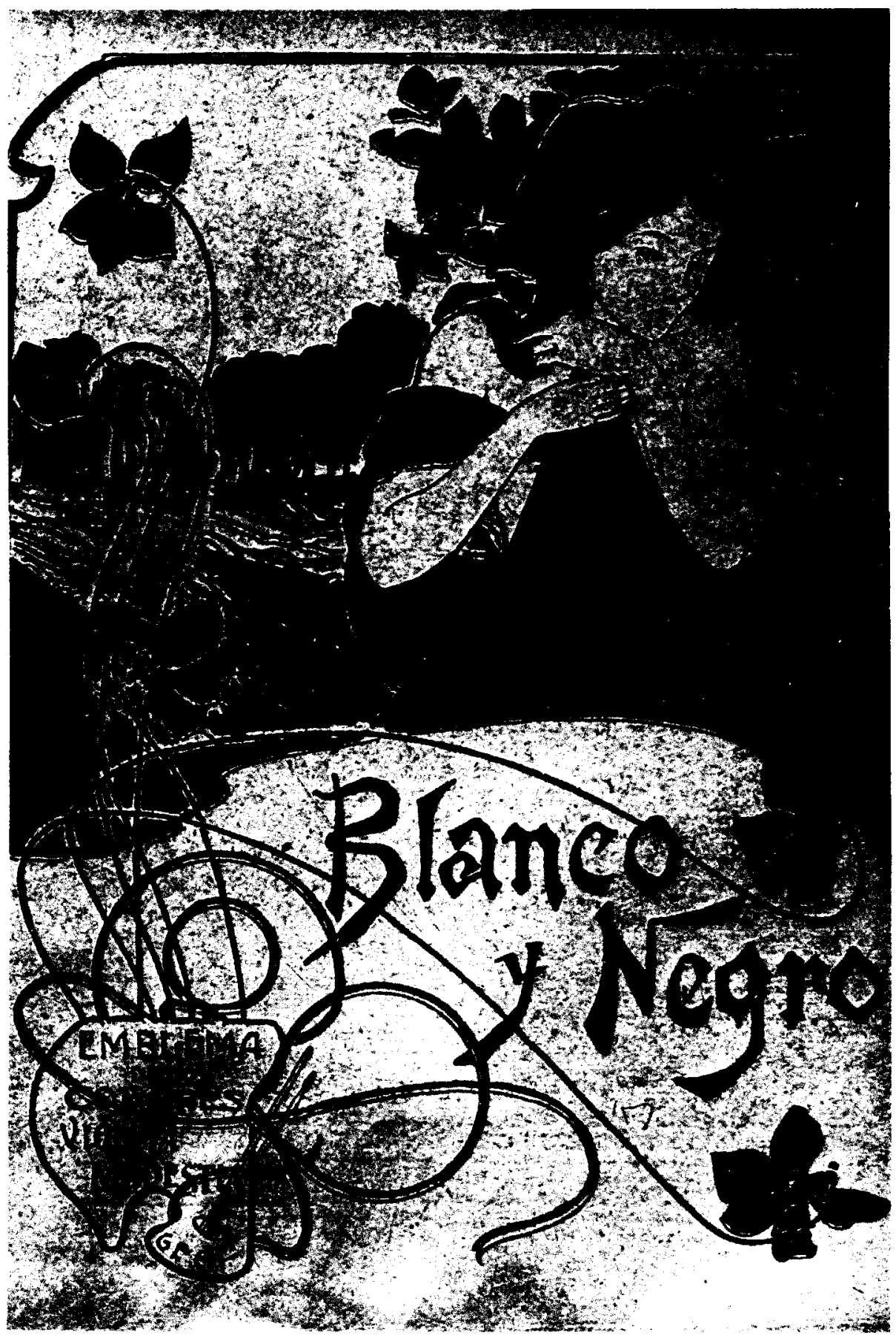

Fig. 6. Chiorino. Portada “Blanco y Negro». (2 marzo, 1901) 


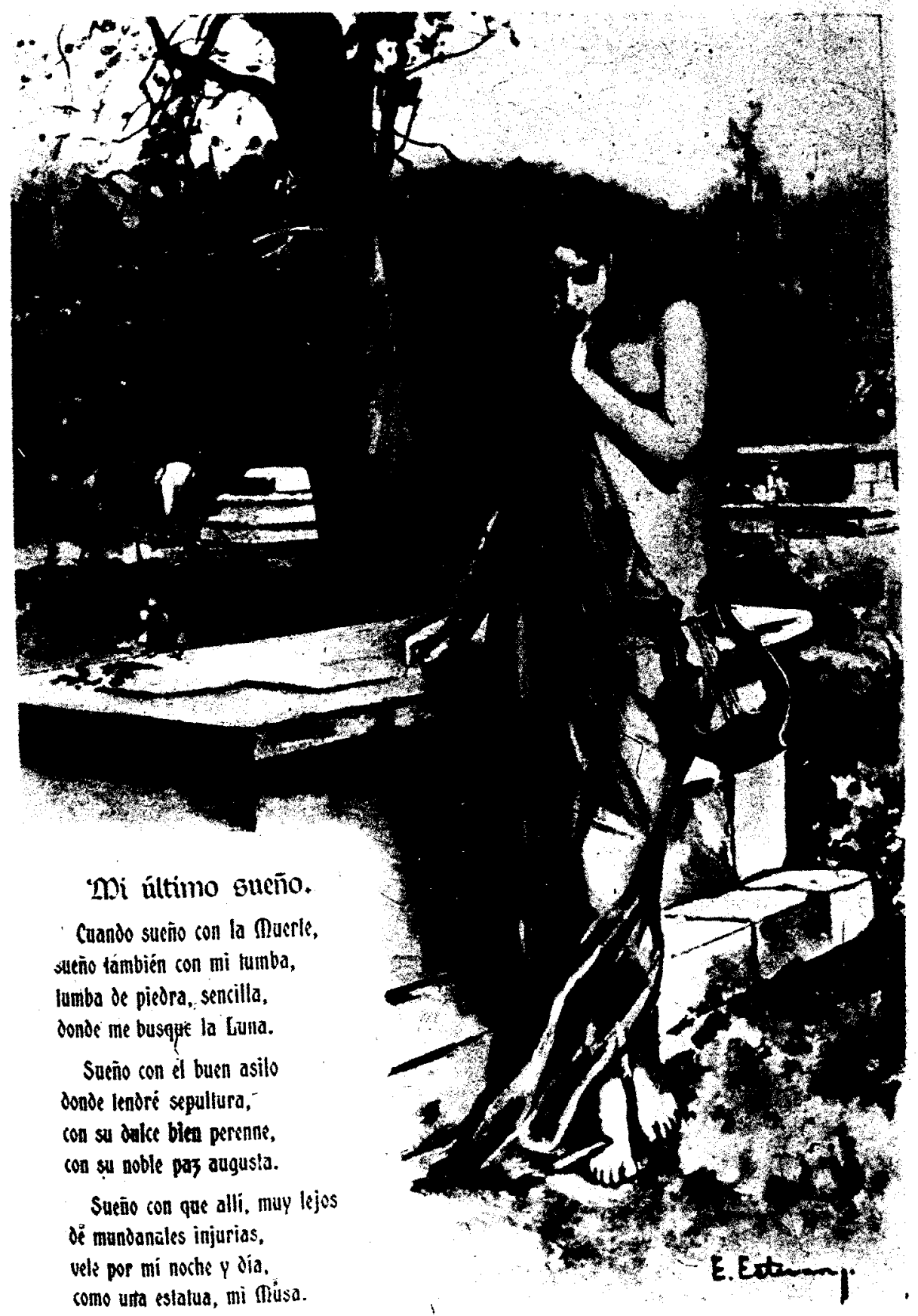

CAKLOE FERNANUEZ SHAW

Fig. 7. Estevan. “Blanco y Negro». 6 noviembre, 1909 


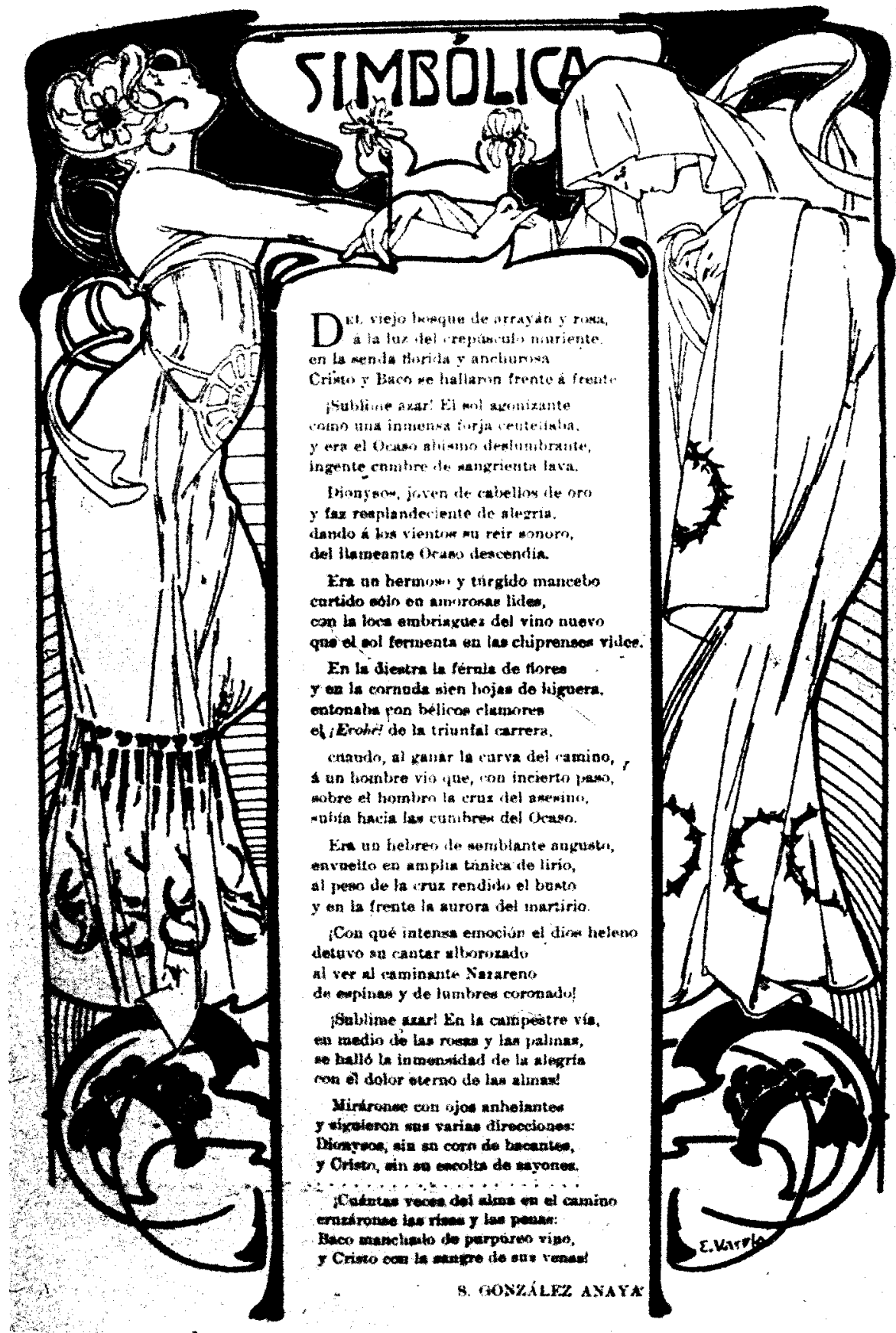

Fig. 8. Varela. "Blanco y Negro". 27 julio, 1901. 


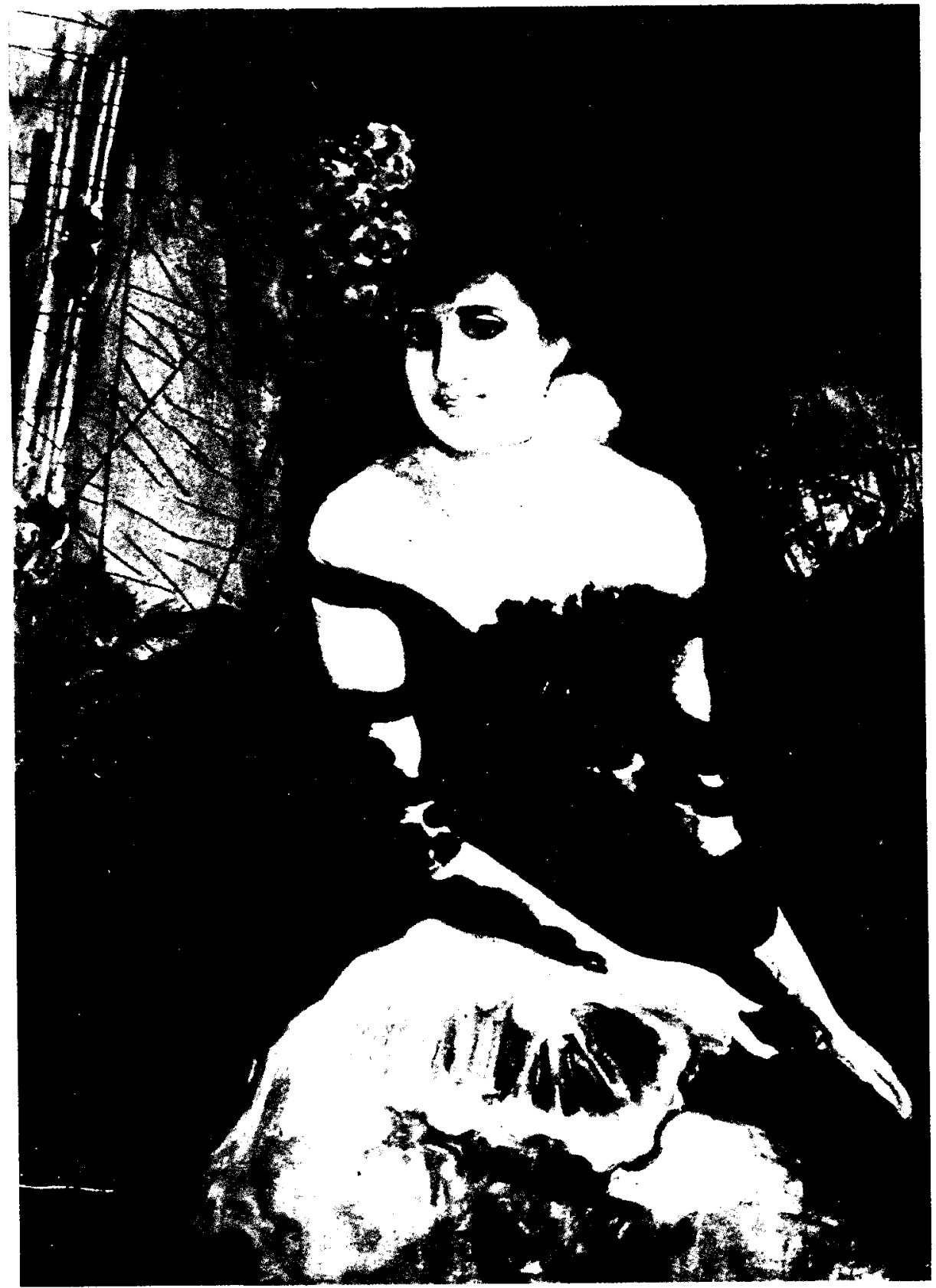

Fig. 9. Pla. Portada “Blanco y Negro». (2 febrero, 1909). 


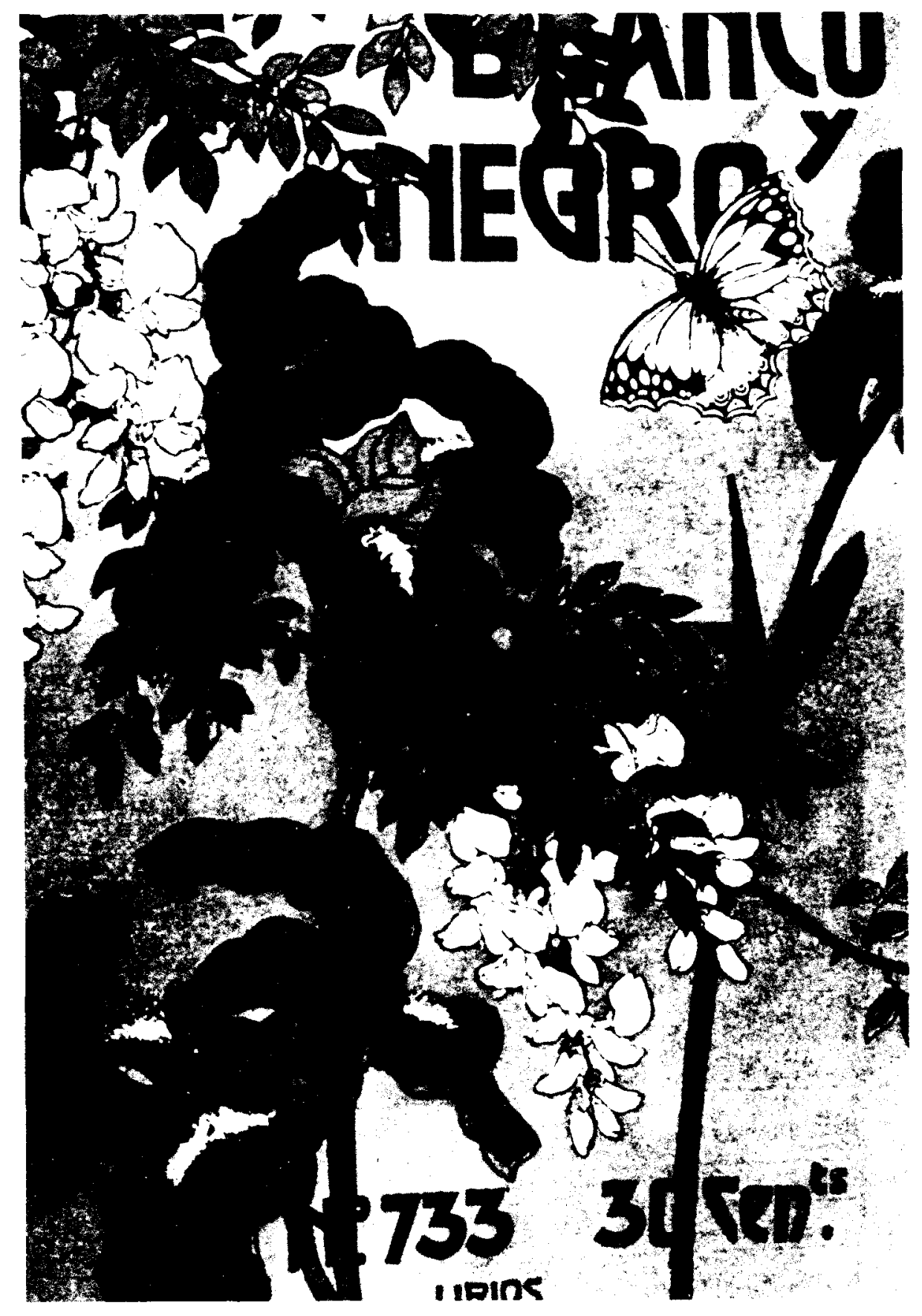

Fig. 10. Regidor. Portada «Blanco y Negro». (20 mayo, 1905). 


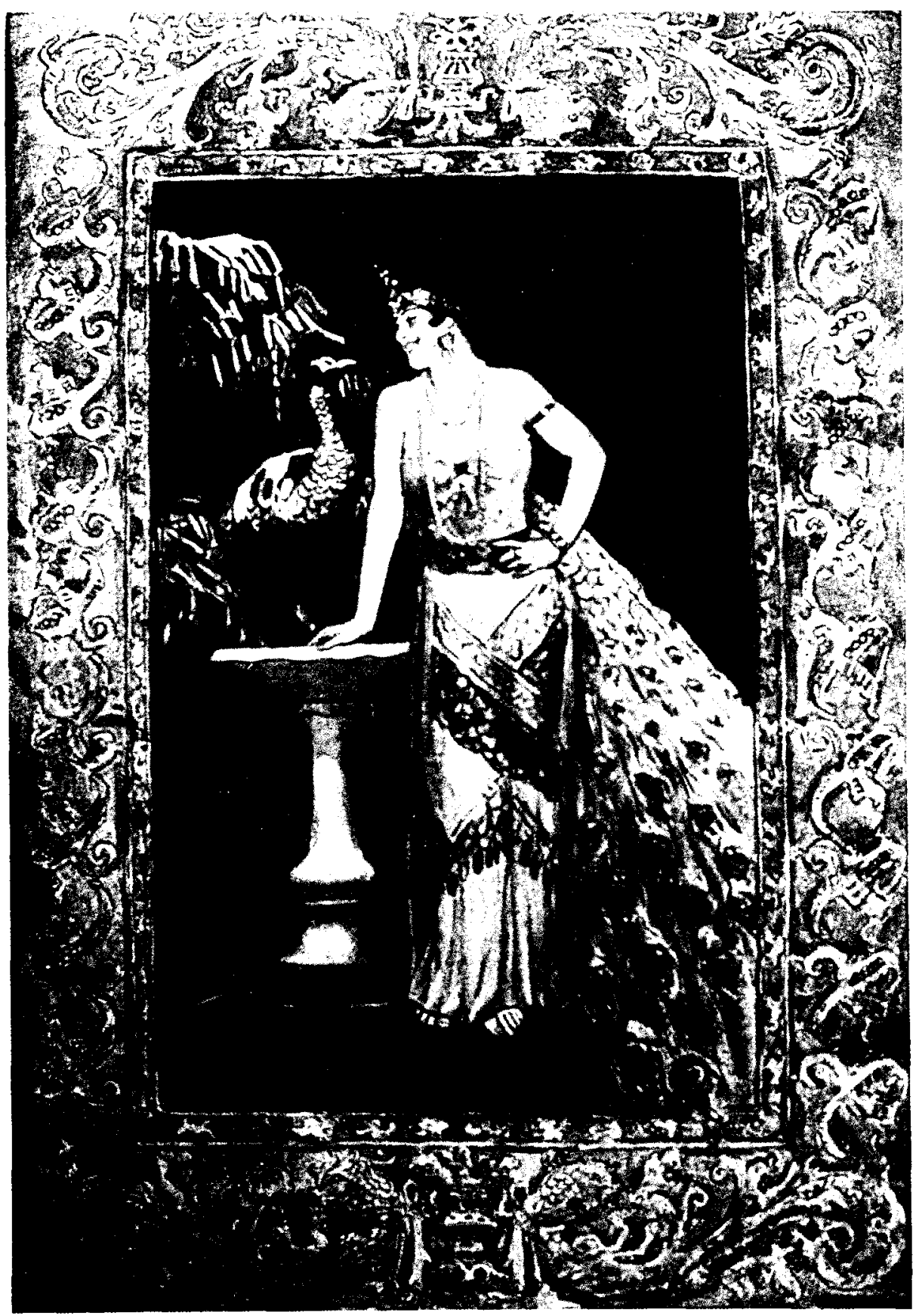

Fig. 11. Huertas. "Blanco y Negro". 2 diciembre, 1917. 


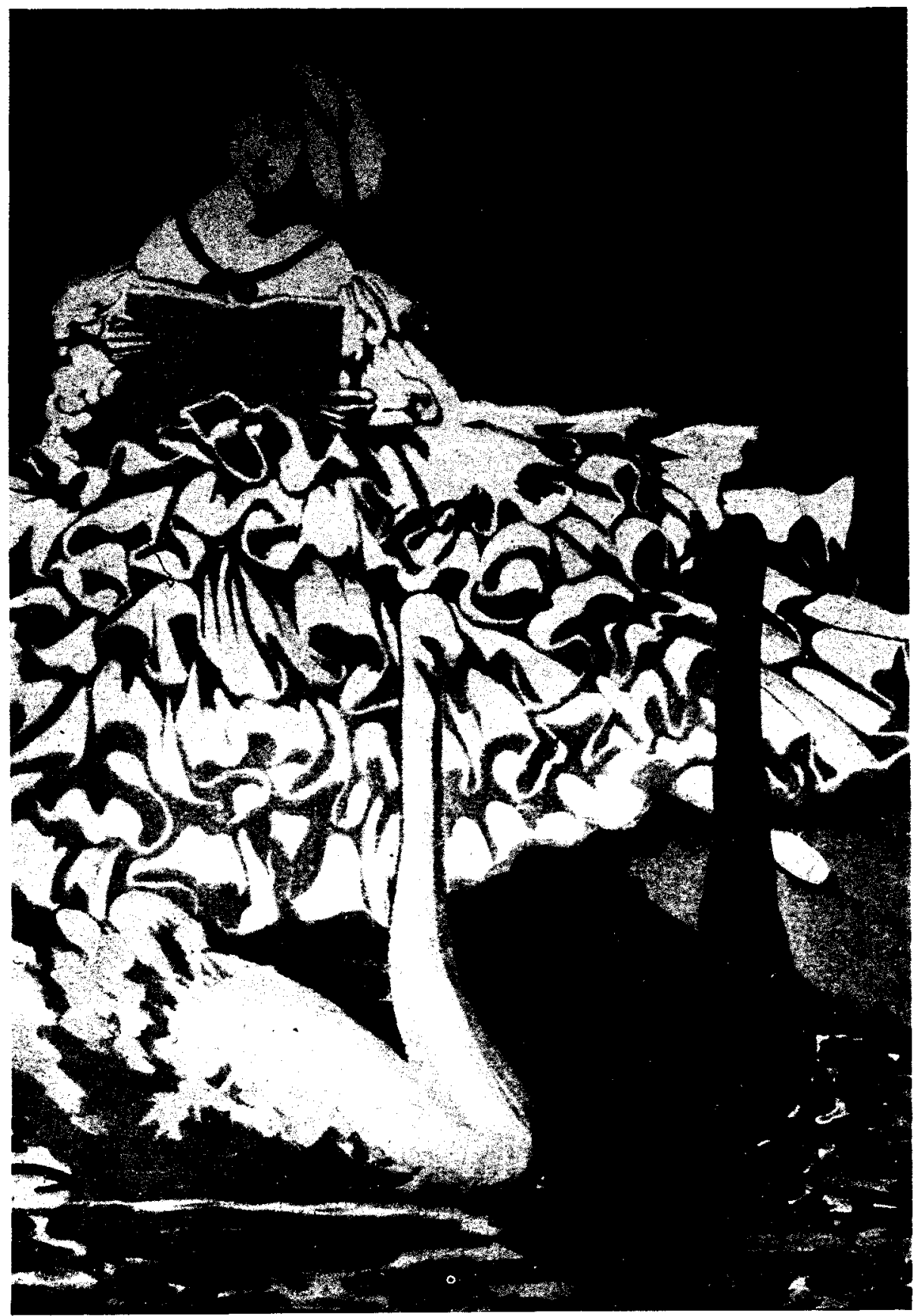

Fig. 12. Ardia. Portada “Blanco y Negro». (9 septiembre, 1917). 


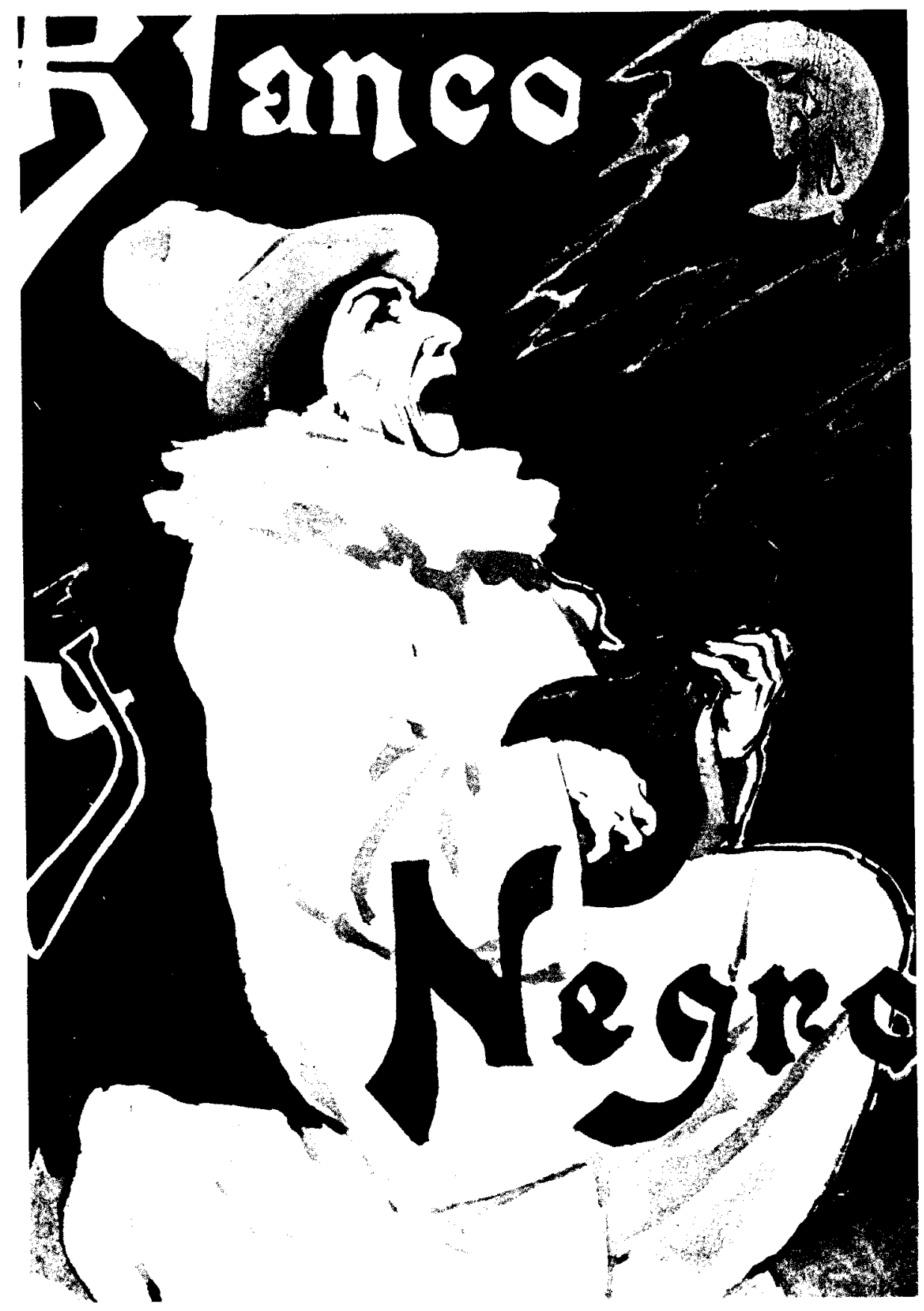

Fig. 13. A. Mestres. Portada “Blanco y Negro". (8 febrero, 1902). 